\title{
The Importance of Information and Communication Technology in Rwanda's Agricultural and Livestock Monitoring in E - Girinka, Gisagara District (2016 - 2019)
}

\author{
Apollos DUSABIMANA ${ }^{1}$, Henry Mapesa $^{2}$ \\ ${ }^{1}$ Rwanda coordinator for International Broadcasting Association (IBRA) \& Communication Officer - Pentecostal Church of Rwanda
} (ADEPR)

${ }^{2}$ Aneriko - Assistant lecturer, Faculty of Journalism and Communication Studies, Department of Journalism and PR, Institut Catholique de Kabgayi (ICK) Rwanda

\begin{abstract}
The word Girinka, loosely translated as "may you have cows, " is a greeting model which is more like a blessing upon those one meets. It was first instituted by King Mibambwe Gisanura (+1660). The King decreed that "no Rwandan child was ever to lack daily milk. Girinka programme was revived in 2006 by President Paul Kagame after realizing the extent of malnutrition and stunting among Rwandan children. Since then, Rwandans have given cattle to one another. Therefore the Innovation diffusion theory was used in the study to explain how the farmers in Gisagara district monitor well their agricultural livestock farming using the Information Communication Technology known as $E$ - Girinka. The last section of this article give recommendations on how $E$ - Girinka program can be improved to give farmers better services.
\end{abstract}

Keywords: Information Communication Technology (ICT), E - Girinka and Livestock.

\section{Introduction}

The use of ICTs particularly radio, television and mobile phones can accelerate agricultural development by improving access to information and knowledge services. They can provide useful and relevant information to solve problems of individual farmers and farming communities by enabling individuals and households to learn and acquire new skills and technologies and also share innovations globally. This will help to foster transfer of knowledge for sustainable and equitable agricultural development and help to bring about increased production in agricultural activities and improved livelihoods of the farmers (Soriano, 2007).

From the perspective of agricultural information and knowledge systems (AKIS), ICT can be seen as a useful tool in improving linkages between research, farmers and agricultural extension systems (Balaji et al, 2007).

ICT build - in linkage through enhancing the exchange of information especially technology among the three domains and make them function as one institution. In research institutes, small extension sections as well as researchextension committees are created, and ICTs such as mobile phone are used to easy communication. Using ICT, the Agricultural extension brings information and new technologies to farming communities, allowing them to improve their production, incomes and standards of living (Materu, 2019).

However, in most places of the country, radio and television continue to be the most common ICTs in rural households. From the past years up to date, radio stations have gained publicity and their numbers have increased which have created more chances of farmers to receive important information needed in boosting their agricultural production New ICTs like the mobile phones were introduced in the mid 1990 (Yonazi, 2009).

As the world continued to shrink in to a global village, the more people are welcoming the new technology which creates the possibilities of integrating rural households into agribusiness. Farmers can use mobile phones to find out information related to market access, bargaining of the suitable price for their commodities by reading information of the current price standings using mobile messages/SMS before trading off their produce. The mobile technologies significantly reduce costs associated with communication and information sharing (Aker, 2010).

Rwanda, a country of thousand hills, is a fast developing African country. According to Rwanda Development Board, (2007), the investment on ICT sector of Rwanda during 2006 , was estimated at $23 \%$. ICT has a significant impact to socio economic performance of the country. This trend has also a positive impact to the agricultural sector thus leading to economic growth, the ICT sector contribution to the GDP was $2.7 \%$, where Rwanda comes as the second top all over the East African region (Usengumukiza, 2009).

Therefore, the researcher were motivated to carry out study mainly to examine the influence of ICT in dissemination agriculture and livestock information to small farmers in Rwanda, Case study of e - girinka Gisagara district.

\section{General objective}

The general objective of this study is to assess the importance of Information Communication Technology in monitoring agricultural livestock farming in Rwanda with the case of E - Girinka in Gisagara District. 


\section{Specific objectives}

The specific objectives of this research are the following:

(i) To identify the effectiveness of ICT tools in the implementation of E - Girinka to farmers in Gisagara District.

(ii) To examine the quality of information provided to farmers in Gisagara District.

(iii) To assess factors affecting the adoption of ICT through E - Girinka in Gisagara District.

(iv) To suggest strategies that can improve the implementation of E - Girinka in Gisagara District.

\section{Research questions}

The study was guided by the following research questions:

(i) What is the effectiveness of E - Girinka as ICT tools to farmers in Gisagara District?

(ii) What are the qualities of information provided to farmers in Gisagara District?

(iii) What are the factors affecting the adoption of ICT through E - Girinka in Gisagara District?

(iv) What are major strategies that can improve the implementation of E - Girinka in Gisagara District?

\section{Review of Related Literature}

\section{(a) The history of girinka programme in Rwanda}

The Government of Rwanda initiatives to address the issues of poverty is based on Rwandan cultural practices and on the only valued resource it possesses the Rwandan population (Corry, 2012). With a decentralisation system of governance, the government of Rwanda has strengthened the participation of its population in problem - solving and development process through participatory approach known as „ubudehe ${ }^{\text {ee }}$ (OSSREA Rwanda Chapter, 2006).

The girinka programme is among many other indigenous empowering programmes initiated by the government of Rwanda. The girinka programme also known as „One Cow

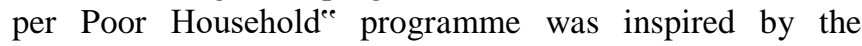
Rwandan culture and initiated by the President of the Republic of Rwanda (RoR) in 2006 and is since then implemented by the Ministry of Agriculture and Animal Resources (MINAGRI) in collaboration with the Ministry of Local Government (MINALOC, 2007).

The inspiration of the programme was based on the results from an Integrated Household Living Conditions Survey II, initially known in French as „Enquête Intégrale sur les Conditions de Vie des Ménages II ${ }^{\mathrm{ee}}$ (EICV2) conducted in 2005 by the National Institute of Statistics of Rwanda (NISR) showing that the rate of rural poverty was substantial with $62.5 \%$ and the rate of childhood malnutrition extremely alarming (NISR, 2005).

The programme was considered an empowering approach for poverty reduction consisting of providing a milk cow to each selected poor household and in turn rotates in giving off their first calves ad infinitum among other neighbouring poor households. The rationale behind this programme was that a cow produces milk and therefore handles the alarming high rate of childhood malnutrition; generates income for a family by selling milk; and provides manure to increase agricultural production. The exotic dairy cow with at least $50 \%$ of genetic makeup was privileged because of its high milk production compared to the local milk cows (Militery, et al., 2013; Republic of Rwanda, RARDA, 2006; Republic of Rwanda, MINAGRI, 2015).

\section{(b) Adoption of ICT tools in agriculture}

According to Hall and Khan (2002), the adoption of technology is the choice to acquire and use a new invention or innovation. The definitions of an adoption vary widely across studies; each study has its own meaning depending on the type of technology that study emphasizes for adoption. When defining "adoption," it can either be a discrete state with binary variables (a farmer either is using a technology, or is not using it, an "adopter") or whether adoption is a continuous measure (Doss, 2003).

It's argued that when at least one of the advanced technologies is used for at least one season, then that can be defined as an adoption. If any farmer is using the technology or not using it, is seen in different ways. According to Doss, 2003, as longer as a farmer is involved with one of any advanced technology, for instance a mobile phone to access agricultural technology, that is adoption. When a farmer uses both local and advanced technologies let us say, a word of mouth and mobile phone to access agricultural technology, that is adoption And when a farmer uses completely advanced technology in accessing information that is an adoption too. In this study, adoption of ICT's cooperates with (Doss, 2003) (Ogunyemi and Ojo, 2014) and (Das, 2014), that is if a farmer uses at least one of advanced information technology, for at least one rice season along with local information technology and completely advanced information technology to access agricultural information, that is termed as an adoption (Ogunyemi and Ojo, 2014).

\section{(c) Importance of information communication} technology in monitoring agricultural livestock farming The use of ICTs particularly radio, television and mobile phones can accelerate agricultural development by improving access to information and knowledge services. They can provide useful and relevant information to solve problems of individual farmers and farming communities by enabling individuals and households to learn and acquire new skills and technologies and also share innovations globally. This will help to foster transfer of knowledge for sustainable and equitable agricultural development and help to bring about increased production in agricultural activities and improved livelihoods of the farmers. (Soriano 2007)

Using ICT, the Agricultural extension brings information and new technologies to farming communities, allowing them to improve their production, incomes and standards of living. From the perspective of agricultural information and knowledge systems (AKIS), ICT can be seen as a useful tool in improving linkages between research, farmers and agricultural extension systems (Balaji et al., 2007).

It is true that the effective use of radio, television, mobile phone and other ICT facilities in agriculture extension services can have a great contribution to the information 
access. For example, studies in rural Thailand and Columbia (ITU, 1999) show that the introduction of telephones enabled farmers to check prices regularly which led to doubling of farm incomes. Lio and Liu (2006) also indicated that the adoption of modern industrial inputs in agricultural production relies on the information and communication infrastructure. (Brynolfsson and Hitt 1995)

In Gisagara district majority of the farmers operate on the small scale level cultivating on fragmented land characterized by low soil fertility. Increasing the efficiency and productivity of small scale farms is an area where ICT can make a significant contribution. (Stienen et al., 2007),

Farming involves risks and uncertainties, with farmers facing many threats from poor soils, drought, erosion and pests. For the farmers to be able to find solutions of the listed problems, the first key improvement is using ICT to provide information about pests and disease control especially early warning systems, new varieties, new ways to optimize production and regulations for quality control. Effective use of ICT can also make farmers identify the market opportunities both within and beyond their local settings. In most cases, the smallholder farmers are unaware of strategic opportunities within their own region and therefore they lack information about; which crops and commodities are fetching higher prices in surrounding towns and which products are in high demand (International Institute for Communication and Development, IICD, 2006).

\section{(d) Telephones and mobile phones}

The telephone system is not only a fundamental communication infrastructure but also a basic facility which supports the use of other technologies. For example, in some African areas, the telephone was the only ICT tool used by most farmers (Bertolini, 2004 cited in Munyua, Adera \& Jensen, 2008). Its advantages included adaptability and the capability of transferring both voice and data at gradually decreasing cost (Mangstl, 2008).

Additionally, mobile communication technologies have become gradually more important in many parts of the world, especially in improving the delivery of information about agriculture (Munyua, Adera \& Jensen, 2008). These communication devices present several advantages such as portability, wide range of coverage and instantaneous two way communications. For instance, mobile phones were used to communicate among Ghanaian fishermen with the purpose of providing each other with information about where to fish, weather conditions and market prices.

Real - time agricultural information and fish prices were also provided through mobile phones in Senegal (Munyua, Adera $\&$ Jensen, 2008). The advice communicated about best place to sell their catch was also utilized by Kerala fishermen in India (Abraham, 2007 cited in Mittal \& Tripathi, 2009; Jensen, 2007 cited in Mittal \& Tripathi, 2009).

Furthermore, the availability of state - of - art technologies, which are now integrated into mobile phones, has further improved communication. Built - in global positioning systems (GPS), high - resolution digital cameras and short length video recorders are exemplary embedded technologies. These advances facilitate the use of mobile phones for sending and receiving voice, text, image and video information (Munyua, Adera \& Jensen, 2008).

\section{Statement of the Problem}

In Rwanda, just like most of Africa countries even though ICT plays a very crucial role in disseminating information about rural Agricultural livestock development in the country, but there is still limited number of qualified and professional ICT communicators and trainers in the country. The rural farmers are also still struggling to fully get the basics of ICT agricultural communication skills and knowledge to in monitor agricultural livestock farming (RMC report, 2018).

After having been fully wrenched of all its resources and infrastructures during 1994, this country's development in ICT sector is astonishing. Mobile phone and Internet penetration rate is more than $100 \%$ in East African countries in the last decade. Rwanda has comparatively high internet penetration in the last decade than any other East African country, which was the appreciable initiative of the government in linking most of the offices and officers and organizations through internet connectivity (EDPRS, 2012).

Seeing the importance of ICT in development, some Districts started to see it as the main tools for achieving the goals of their performance contracts (Imihigo). In that case Gisagara District initiated E - Girinka in management of Girinka program with the aim of solving all problems/challenges that are met in Girinka program implementation. Basing on that background, this study will examine the effectiveness of E - Girinka program in disseminating quality and reliable information to small farmers especially the beneficiaries of Girinka Program initiated in 2006 by H. E. Paul Kagame in response to the alarmingly high rate of childhood malnutrition and as a way to accelerate poverty reduction and integrate livestock and crop farming.

\section{Methodology of Data Collection}

\section{(a) Study area}

This research was conducted in Gisagara is a district (Akarere) in Southern Province, Rwanda. The district lies just to the East of Butare town, along the border with Burundi. The study focused on farmers and stakeholders in agriculture in Gisagara District where in total where found to 1023 meaning 950 beneficiaries of Girinka and 73 stakeholders (District development plan report, 2018).

\section{(b) Research design}

Kumar (2011) argues that, Research design is a predefined plan that is used by order to come up with the outcome or the results of the research study. Hence this research was descriptive one where quantitative and qualitative data will be interpreted to reach the objectives of this study.

\section{(c) Study population}

According to O'Leary (2004) population is the aggregate membership of a distinct class of people, objects, or event. The target population of this research was composed of 
farmers and stakeholders in agriculture in Gisagara District where in total where found to 1023 meaning 950 beneficiaries of Girinka and 73 stakeholders.

\section{(d) Sampling techniques}

Generally, deciding on a sample is not given to arbitrariness but by strict adherence to laid down principles (Nwankwo, 2006). Therefore, the sample for this study was determined using the

Taro Yamen's formula for drawing sample (Nwankwo, 2006):

$\mathrm{n}=\mathrm{N} /\left(1+\mathrm{N}(\mathrm{e})^{2}\right)$

Where;

$\mathrm{n}=$ sample size,

$\mathrm{N}=$ sampled population and

$\mathrm{e}=$ error tolerance.

In this case, the research proceeded with an error of $10 \%$ and confidence coefficient of $80 \%$. The estimated sample population will be $\mathrm{N}=1023$. Therefore, the sample population $(\mathrm{n})$ was;

$\mathrm{n}=1023 /\left(1+1023(0.1)^{2}\right)$

$\mathrm{n}=1023 /(1+1023(0.01)$

$\mathrm{n}=1023 /(1+10.23)$

$\mathrm{n}=1023 / 11.23$

$\mathrm{n}=91.09$

$\mathrm{n}=91$.

As shown in the above calculations, the study sampled a minimum of 91 respondents who were 81 farmers and 10 stakeholders in agriculture in Gisagara District.

\section{Data collection instruments}

They are tools used by the researcher to gather data from the respondents and other source that are relevant to the study. The Questionnaires, Documentation and Interview were used for data collection.

\section{Findings and Solutions}

\section{(a) Findings related to specific objectives}

The first objective guiding the study aimed at identifying the effectiveness of ICT tools in the implementation of E Girinka to farmers in Gisagara District. Statistics indicate that 30 respondents interviewed believe that ICT tools of e girinka enable farmers to use their phones to call and receive information about their agricultural livestock farming in Gisagara district with $35 \%$. then 27 respondents said that, ICT tools of e - girinka enable farmers to send sms text and share information their agricultural livestock farming in Gisagara district with $30 \%$. Also 14 respondents interviewed believe that, ICT tools of e - girinka enable farmers to send recorded voices through their mobile phones of information their agricultural livestock farming in Gisagara district with $15 \%$. Then 10 respondents said that, ICT tools of e - girinka enable farmers to receive, read and learn about agricultural livestock farming in Gisagara district through their smart phones with $11 \%$. Last but not least, 8 respondents revealed that, ICT tools of e - girinka enable farmers to report issues about agricultural livestock farming problems to district veterinary doctor with $9 \%$.

The second objective guiding the study aimed at examining the quality of information provided to farmers in Gisagara District. The study found out that, 30 respondents interviewed said that, Information is provided on time to farmers in Gisagara District with 33\%. Then, 24 respondents mentioned that, the information provided meets the government agricultural standards and the needs of farmers in Gisagara District with 26\%. Also 16 respondents said that, the information provided is well researched with professional government agricultural officers, reliable and accurate with $18 \%$. Then, 12 respondents mentioned that, the information provided is put in understandable language with pictures for the farmers in Gisagara district with $13 \%$. Last but not least, 9 respondents believe that, E - Girinka system provide information of access to land records/registration online of the beneficiaries with $10 \%$.

The third objective guiding the study aimed at assessing factors affecting the adoption of ICT through E - Girinka in Gisagara District. Statistics reveal that, 26 respondents interviewed said that, there is inadequate financial support to run ICT programs through E - Girinka in Gisagara District with $33 \%$. Then, 24 respondents mentioned that, there is shortage of land among E - Girinka families which affects some beneficiaries to access the program in Gisagara District with $26 \%$. Also, 18 respondents believe that, there is corruption among some E - Girinka leaders which affect some beneficiaries to have adoption of ICT through E Girinka in Gisagara with 18\%. Furthermore, 16 respondents said that, Lack of proper and adequate technological skills and knowledge among E - Girinka leaders and farmers with $13 \%$. Last but not least, 7 respondents think that, there is inadequate policy framework to guide ICT usage in E Girinka with $10 \%$.

The fourth objective guiding the study aimed at suggesting strategies that can improve the implementation of $\mathrm{E}$ Girinka in Gisagara District. Statistics indicate that 20 respondents interviewed said that, conduct regular sensitization and training workshops for the farmers about the use of E - Girinka in Gisagara district with $22 \%$. Then 26 respondents revealed that, conduct site visits to areas that have successfully adopted ICT of E - Girinka in Gisagara district with 29\%. Furthermore, 22 respondents also said that, engage service providers in long term service level agreements for the farmers about the use of E - Girinka in Gisagara district with24\%. Also 15 respondents revealed that, adopt technologies that have adequate local support for the farmers about the use of E - Girinka in Gisagara district with $16 \%$. Lastly, 8 respondents interviewed said that, Hire adequate IT support staffs to enable them give good services to farmers about the use of E - Girinka in Gisagara district with $9 \%$. The study concluded that, the information provided is well researched with professional government agricultural officers, reliable and accurate.

\section{(b) Solutions}

\section{To Rwandan Government through E - Girinka program} leaders

- Socio - economic characteristics of the farmers such as age, sex, education level and marital status should be considered when planning for different programs that involve radio, television and mobile phone in provision of agricultural information to farmers. The extension 
staff should think of the right type of ICT to use when communicating to a particular group of farmers.

- Policy makers should put in place enabling regulations which will facilitate development planners to formulate strategies targeting the use of ICT as one of innovative communication pathways that have been adopted in monitoring agricultural livestock farming in Rwanda hence increased agricultural products.

- It would be better when the local leaders visit more often the participants in order to know what the needs are or what the benefits and know the way forward. There should be enough trainings for the participant in the program, because most of them, it is their first time to take care of a cow.

- Seek for Aid: More organizations and individuals should be encouraged by the government of Rwanda to give donations E - Girinka Program (one cow per family) in Rwanda in order to reduce poverty among citizens.

- Build capacity of Girinka beneficiaries to ensure better management of cows (health, feeding and reproduction) through trainings on breeding, nutrition, housing, management and record keeping; and provide them supplementary package such as artificial insemination inputs and feeds, for an increased dairy produce.

- Set up Monitoring and Evaluation systems for the programme (E - Girinka web - based and SMS application) and improve coordination and monitoring of the programme.

- To deepen and increase financial literacy and inclusion (Saving and Loan services) of beneficiaries, as cows can be a stable source of income.

\section{To the Researchers}

The academicians strengthen studies in the area of information communication technology in monitoring agricultural livestock farming in Rwanda which lacks adequate literature for researchers in mass communication.

\section{To community (Farmers)}

Farmers should take initiatives in using the available ICTs to seek for various agricultural information that they think can help them to improve their agricultural practices. They should use their mobile phones to communicate with extension staff, input dealers and other farmers. They should also listen or watch various agricultural programs on the radio and television.

\section{Conclusion}

There is a need for further study on how the ICTs can effectively work together. Since the ICTs are dynamic as a result of the globalization, there is need to upgrade the E Girinka Program (one cow per family). This will help to overcome the shortcomings in each ICT thus knowledge and information exchange will be enhanced. In addition, this will help to inform and guide the best ICT model for easy information flow between the farmers and other stakeholders in agriculture sector.

\section{Future Scope}

This study could be extended by looking into related topics in Mass Communication like:

1) The power of documentary films on educating farmers about agricultural livestock farming in Rwanda.

2) The power of radio broadcast on educating farmers about agricultural livestock farming in Rwanda.

3) The use of smartpnone on educating farmers about agricultural livestock farming in Rwanda.

4) The power of TV broadcast on educating farmers about agricultural livestock farming in Rwanda.

\section{References}

[1] Aker, J. (2010). Dial “A” for Agriculture: Using Information and Communication Technologies for Agricultural Extension in Developing Countries.

[2] Barakabitze, A. A., Kitindi, E. J., Sanga, C., Shabani, A., Philipo, J. and Kibirige, G. (2015) New Technologies for Disseminating and Communicating Agriculture Knowledge and Information (AKI): Challenges for Agricultural Research Institutes (ARI) in EJISDC (2017)

[3] Churi, A. J., Mlozi, M. R. S., Tumbo, S. D., Casmir R. (2012). Understanding Farmers

[4] Dr. Nyabinwa P. (November, 2016), Overview of One cow per poor family programme. Retrieved from http: //www.minagri. gov. rw

[5] Esselaar, P., Hesselmark, O., James, T. and Miller J. (2001). Final report: A three country

[6] FAO (2010). Mobilizing the potential of rural and agricultural extension. Rome.

[7] ICT survey for Rwanda, Tanzania and Mozambique.

[8] IICD (2006). ICT for Agricultural Livelihoods: Impact and lessons learnt from IICD supported

[9] Information.

[10] RGB. (2016). Rwanda Media Barometer. Kigali: RGB. 